\title{
DIREITO À EDUCAÇÃO INCLUSIVA NO MERCOSUL
}

\author{
Right to inclusive education in Mercosur
}

\author{
Derecho a la educación inclusiva en el Mercosur
}

\author{
Washington César Shoiti Nozu* \\ Albert Vinicius Icasatti** \\ Kellcia Rezende de Souza***
}

\begin{abstract}
Resumo
Nas últimas décadas, a educação inclusiva vem sendo disseminada discursivamente, no âmbito internacional, como um recurso corolário da universalidade do direito à educação, previsto na Declaração Universal dos Direitos Humanos de 1948. Diante das exigências provocadas pelo mundo globalizado, as organizações intergovernamentais têm direcionado atenção para a educação, sobretudo, como um elemento de integração e de desenvolvimento econômico. Nesse contexto, o presente artigo tem como objetivo analisar a abordagem do direito à educação inclusiva veiculada na documentação produzida pelo Setor Educacional do Mercado Comum do Sul (Mercosul). Para tanto, a configuração metodológica desse trabalho percorreu os quatro últimos Planos de Ação do Setor Educacional do Mercosul (2001-2005; 2006-2010; 2011-2015; 2016-2020). Os resultados sugerem a vinculação da educação inclusiva ao fortalecimento da integração e da circulação de bens e serviços na região. Ainda, evidenciam lacunas na produção documental do referido bloco no tratamento da educação inclusiva, principalmente quanto aos conceitos e ao modus operandi para sua consecução. Por fim, o estudo problematiza a visão da educação inclusiva enquanto redentora dos dilemas sociais.
\end{abstract}

PALAVRAS-CHAVE: Direito à Educação. Educação Inclusiva. Políticas Educacionais.

\begin{abstract}
In the last decades, inclusive education has been discursively disseminated at the international level as a corollary of the universality of the right to education, predicted in the Universal Declaration of Human Rights of 1948. Facing the demands of the globalized world, intergovernmental organizations have directed attention to education, especially as an integration element and economic development. In this context, this article aims to analyze the approach to the right to inclusive education in the documentation produced by the Education Sector of the Common Market of the South (Mercosur). To that end, the methodological configuration of this work covered the last four Action Plans of the Mercosur Educational Sector (2001-2005, 2006-2010, 2011-2015, 2016-2020). The results suggest the linkage of inclusive education to the strengthening integration and circulation of goods and services in the region. Still, they show gaps in the documentary production of this block in the treatment of inclusive education, especially in terms of concepts and modus operandi for its

\footnotetext{
* Universidade Federal da Grande Dourados (UFGD), Dourados/MS - Brasil. Docente da Faculdade de Educação e do Programa de Pós-Graduação em Fronteiras e Direitos Humanos. Doutor em Educação pela UFGD. Bolsista Pesquisador Ingressante da UFGD, na área de Ciências Humanas. E-mail:

WashingtonNozu@ufgd.edu.br.

** Universidade Federal da Grande Dourados (UFGD), Dourados/MS - Brasil. Mestrando pelo Programa de Pós-Graduação em Fronteiras e Direitos Humanos. E-mail: albert_ksat@ @otmail.com.

*** Universidade Federal da Grande Dourados (UFGD), Dourados/MS - Brasil. Docente da Faculdade de Educação. Doutora em Educação Escolar pela Universidade Estadual Paulista Júlio de Mesquita Filho Unesp/Araraquara. E-mail: kellciaSouza@ufgd.edu.br.
} 
achievement. Finally, the study problematizes the view of inclusive education as a redemptive of social dilemmas.

KEYWORDS: Right to Education. Inclusive Education. Educational Policies.

\section{Resumen}

En las últimas décadas, la educación inclusiva viene siendo diseminada discursivamente, en el ámbito internacional, como un recurso corolario de la universalidad del derecho a la educación, previsto en la Declaración Universal de los Derechos Humanos de 1948. Ante las exigencias provocadas por el mundo globalizado, las organizaciones intergubernamentales han dirigido atención a la educación, sobre todo como un elemento de integración y de desarrollo económico. En este contexto, el presente artículo tiene como objetivo analizar el abordaje del derecho a la educación inclusiva vehiculada en la documentación producida por el Sector Educativo del Mercado Común del Sur (Mercosur). Para ello, la configuración metodológica de ese trabajo recorrió los cuatro últimos Planes de Acción del Sector Educativo del Mercosur (2001-2005, 2006-2010, 2011-2015, 2016-2020). Los resultados sugieren la vinculación de la educación inclusiva al fortalecimiento de la integración y de la circulación de bienes y servicios en la región. Sin embargo, evidencian lagunas en la producción documental de dicho bloque en el tratamiento de la educación inclusiva, sobre todo en cuanto a los conceptos y al modus operandi para su consecución. Por último, el estudio problematiza la visión de la educación inclusiva como redentora de los dilemas sociales.

PALABRAS CLAVE: Derecho a la Educación. Educación Inclusiva. Políticas Educativas.

\section{INTRODUÇÃO}

O Mercado Comum do Sul (Mercosul) foi criado pelo Tratado de Assunção, em 1991, com o objetivo de formar uma área de livre circulação de pessoas, bens, produtos, serviços e capitais entre os países do Cone Sul, por meio da eliminação de barreiras alfandegárias e restrições não tarifárias de mercadorias. Originariamente, o Mercosul foi formado pela Argentina, Brasil, Paraguai e Uruguai. Em 2012, a Venezuela aderiu ao Tratado de Assunção, sendo, portanto, o quinto país a integrá-lo na condição de membro ${ }^{1}$.

Trata-se de uma organização intergovernamental formada para fortalecer a economia de seus respectivos membros, pois, como assevera Babinski (2010), os blocos regionais surgem como resposta à dificuldade de enfrentar questões complexas, encaradas pelos países, referentes ao mundo globalizado, o que inclui as áreas econômica, social e ambiental, que vão além da esfera nacional.

Embora a ênfase eminente do Mercosul seja o setor econômico e comercial, tendo em vista sua proposta de promover integração econômica entre os Estados-membros, incorpora, desde o início, outros setores que possuem estrita relação com o fortalecimento cultural e social do bloco, dentre eles, a educação.

Dessa maneira, o Mercosul delega à educação uma importante função para o êxito de seus objetivos, reconhecendo a necessidade de instruir a população, preparando-a com as devidas competências para a inserção no mercado global, de modo que possam auxiliar na circulação de bens, produtos, serviços, capitais e pessoas e, também, se beneficiar com o esperado desenvolvimento econômico e social (MATEUS, 2008).

A educação foi incorporada na pauta do Mercosul a partir da criação do Setor Educacional do Mercosul. Este Setor constitui-se em um espaço institucional de

\footnotetext{
${ }^{1} \mathrm{O}$ recorte do estudo delimita apenas os países pertencentes ao Mercosul. Dessa forma, não atentaremos à discussão dos Estados Associados - Chile, Bolívia, Colômbia, Equador e Peru, assim como os demais países latino-americanos, cuja realidade econômica, social e, dentro desta, educacional, apresenta muitos traços de similaridade (BABINSKI, 2010).
} 
coordenação de políticas educacionais dos países membros, mediante a regulamentação de Planos de Ação, instrumentos que objetivam garantir, por meio de definições de estratégias e metas, um espaço educacional integrado.

Em face dessas considerações, o presente artigo tem como objetivo analisar a abordagem do direito à educação inclusiva veiculada na documentação produzida pelo Setor Educacional do Mercado Comum do Sul (Mercosul).

Para tanto, a configuração metodológica desse trabalho percorreu os quatro últimos Planos de Ação do Setor Educacional do Mercosul (2001-2005; 2006-2010; 2011-2015; 2016-2020), considerando que os dois primeiros planos (1992-1994, prorrogado até 1997, e 1998-2000) não fazem alusão à questão da educação inclusiva.

A expressão "educação inclusiva" é construída discursivamente no bojo do movimento de "educação para todos", amplamente disseminado no âmbito internacional por meio de declarações elaboradas pela Organização das Nações Unidas para a Educação, a Ciência e a Cultura (UNESCO), a partir da década de 1990.

A educação inclusiva refere-se a um objetivo político a ser alcançado (BUENO, 2008), qual seja, o de que todo ser humano tenha seu direito à educação garantido e efetivado. Nesse sentido, "seu pressuposto básico é de que todas as escolas devem adaptarse para atender a todos os alunos, independentemente de suas condições físicas, intelectuais, sociais, emocionais, linguísticas etc" (GLAT; PLETSCH, 2011, p. 19). Assim, a "construção de uma educação inclusiva requer mudanças nos processos de gestão, na formação de professores, nas metodologias educacionais, etc. com ações compartilhadas e práticas colaborativas que respondam às necessidades de todos os alunos" (HEREDERO, 2010, p. 197).

A análise proposta revela-se importante, considerando que a educação inclusiva ainda é um desafio mundial, mas de forma mais acentuada nos países mais pobres, onde a presença de crianças e adolescentes em situação de vulnerabilidade social e marginalizadas do sistema educacional é maior (AINSCOW, 2009).

Portanto, destaca-se a necessidade de elucidar estudos que explorem a educação inclusiva e suas relações no plano internacional, dada a implantação de políticas públicas na garantia do direito à educação, assim como na configuração e no entendimento dessas relações transnacionais. Assim, na sequência, apresentam-se os dados em dois eixos de análises: a) Direito Humano à Educação; b) Direito à Educação Inclusiva nos Planos de Ação do Setor Educacional do Mercosul.

\section{Direito Humano à Educação}

A educação constitui-se numa instância tipicamente humana. Para Nozu, Icasatti e Bruno (2017, p. 23), "é mediante o processo educativo que constituímos a nossa condição humana, com a apropriação e transmissão de saberes, costumes, valores, usos, conhecimentos e práticas que se dão nas relações sociais com outros seres humanos".

Dado seu status de essencialidade na constituição do ser humano, a educação integra, por meio do Art. 26, o rol de prerrogativas atinentes à defesa e promoção da dignidade expresso na Declaração Universal dos Direitos Humanos (DUDH), de 1948. Neste documento internacional, a educação é aclamada como um direito universal.

Desde então, os países vinculados à Organização das Nações Unidas têm se mobilizado na disseminação da educação enquanto, simultaneamente, um direito humano per si e uma chave para abertura de outros direitos considerados essenciais, sobretudo por 
meio do movimento denominado "educação para todos", a partir da década de 1990 (SCHILLING, 2008; NOZU; ICASATTI; BRUNO, 2017).

Dentre as declarações de "educação para todos", produzidas sob a regência da UNESCO, destacam-se, cronologicamente: a Declaração de Jomtien, fruto da Conferência Mundial sobre Educação para Todos, realizada em 1990, na Tailândia; a Declaração de Dakar, resultante da Cúpula Mundial de Educação promovida no Senegal, no ano 2000; a Declaração de Incheon, produto do Fórum Mundial de Educação, que ocorreu em 2015 na Coreia do Sul.

Conforme Souza, Nozu e Kerbauy (2018, p. 178-179),

Resguardadas as especificidades restritas a cada uma das declarações, é possível identificar uma linha contínua que é evidenciada em todos os documentos, que objetiva estabelecer um conjunto de políticas coordenadas entre os Estados signatários, com o foco voltado para as seguintes ênfases: garantia do direito à educação para todos e a melhora competitiva a partir da educação, concebendo o gasto educacional como promotor de justiça social, como um investimento no fator produtivo, assim como um potencializador da integração entre os países.

Dessa forma, Momma (2001) esclarece a vinculação da educação como elemento integrador das políticas internacionais. Por sua vez, Akkari (2011, p. 24) explica que os movimentos globais, sobretudo de ordem econômica, enraízam-se no âmbito dos sistemas educacionais, já que "as mudanças na educação são discutidas em diferentes esferas exteriores à escola, incluindo grupos políticos, sociais e financeiros".

Ainda, cabe enfatizar que, ao longo de 15 anos, as Declarações de Jomtien (1990), de Dakar (2000) e de Incheon (2015), progressivamente, passam a enfatizar a expansão do direito à educação de qualidade, equitativa e inclusiva. Aliás, sobre este último adjetivo, é primordial que, neste ínterim, seja feita menção à Declaração de Salamanca, tida como a certidão de nascimento da proposta de educação inclusiva (NOZU; ICASATTI; BRUNO, 2017).

A Declaração de Salamanca, resultado da Conferência Mundial sobre Necessidades Educativas Especiais: Acesso e Qualidade, promovida em 1994, na cidade de Salamanca, Espanha, reitera o direito universal à educação, sinalizando atenção particular às populações historicamente alijadas do processo de escolarização, dentre as quais são salientadas aquelas com deficiência, com superdotação, moradoras de rua, de origens remotas ou nômades, pertencentes a minorias linguísticas, étnicas ou culturais, de grupos desavantajados ou marginalizados (UNESCO, 1994).

Nessa perspectiva, Ainscow (2009) indica a inexistência de consenso na definição de educação inclusiva e elenca cinco concepções recorrentes no âmbito internacional: a) educação inclusiva como proposta adstrita aos alunos com deficiência, transtornos do espectro autista e altas habilidades/superdotação; b) educação inclusiva como resposta a exclusões de alunos indisciplinados; c) educação inclusiva como bandeira de todos os grupos vulneráveis à exclusão; d) educação inclusiva como forma de combate ao sistema de escolas classificatórias, organizadas com base nos diferentes níveis de desempenho dos estudantes; e) educação inclusiva como educação para todos.

Na proposta da educação inclusiva, a ênfase nas mudanças recai sobre as escolas, que se constituem em "meios mais eficazes de combater atitudes discriminatórias criando-se comunidades acolhedoras, construindo uma sociedade inclusiva e alcançando educação para todos" (UNESCO, 1994). Tem-se aqui uma visão acrítica da relação entre educação e sociedade, que compreende a primeira como redentora da realidade social. Assim, num cenário em que a "sociedade inclusiva passou a ser considerada como um processo de 
fundamental importância para o desenvolvimento e a manutenção do estado democrático, a educação inclusiva começou a se configurar como parte integrante e essencial desse processo" (MENDES, 2010, p. 105).

Considerando que a criação das políticas educacionais se dá mediante um processo de "bricolagem", com uso de ideias, textos, discursos, fragmentos e abordagens que são recontextualizadas e reinterpretadas nas relações macro e micropolíticas (BALL, 2001), em seguida, serão tecidos alguns apontamentos a respeito dos desdobramentos do direito à educação inclusiva na documentação específica do Mercosul.

\section{Direito à Educação Inclusiva nos Planos de Ação do Setor Educacional do Mercosul}

Contemplada nos documentos oficiais do Mercosul como um dos elementos chave para o processo de integração regional entre os países, a educação é concebida, com tom salvacionista, como solução para a superação das disparidades regionais e para a consolidação da democracia no contexto do bloco (MOMMA, 2001).

Com efeito, conforme Beshara e Pinheiro (2008), em 13 de dezembro de 1991, apenas oito meses após a assinatura do Tratado de Assunção, foi constituído o Setor Educacional do Mercosul, por meio do Protocolo de Intenções firmado pelos Ministros da Educação dos Estados-membros, o qual ficou responsável pela elaboração de Planos de Ação para a Educação. Estes documentos informam as estratégias, os princípios e os resultados esperados pelo acordo, além de avaliar os projetos educacionais concluídos ou em processo de execução.

O Setor Educacional do Mercosul foi criado com base na ideia de que a integração regional não deve estar circunscrita aos aspectos econômicos e políticos, mas deve abrigar, também, iniciativas culturais, educativas e sociais. Nesse sentido, o Protocolo de Intenções previu que a educação tem papel fundamental para que a integração se consolide e se desenvolva. (BESHARA; PINHEIRO, 2008, p. 3)

O Setor Educacional do Mercosul apresenta uma organização institucional que abrange várias comissões que tratam das especificidades educacionais (Níveis de Ensino, Modalidades, Financiamento, Avaliação, Gestão, Currículo e Educação Especial). Suas ações resultam na elaboração de Planos Plurianuais de Ação, que traçam linhas estratégicas para nortear a definição das políticas educacionais nos países membros do bloco. Desde a sua criação foram sistematizados seis Planos de Ação, sendo que os dois primeiros tiveram vigência de dois anos e os quatro últimos passaram a contemplar um período de cinco anos.

Antes de compreender, particularmente, os quatro últimos Planos de Ação do bloco, é importante apresentar, em linhas gerais, as diretrizes estabelecidas nos dois primeiros documentos normatizados pelo Setor Educacional. O primeiro Plano de Ação foi assinado em 1992, com previsão de vigorar até 1994. No entanto, conforme decisão da Comissão de Ministros da Educação, foi prorrogado até 1997. O documento apresentou, como proposições, a centralização na formação de uma consciência social favorável ao processo de integração regional; a capacitação de recursos humanos objetivando contribuir no desenvolvimento econômico; e a harmonização dos sistemas educativos dos países membros (BESHARA; PINHEIRO, 2008).

Gadotti (2007) salienta ainda que esse plano destacou o papel estratégico desempenhado pela educação no processo de integração, para alcançar o desenvolvimento econômico, social, científico-tecnológico e cultural da região. Em 1998, entrou em vigor o novo plano, substituído posteriormente pelo de 2001-2005. Esses dois planos apresentavam 
características e proposições muito próximas ao primeiro, cujo principal problema destacado referia-se às grandes disparidades educacionais existentes entre os Estados, demandando compromissos entre os países membros do Mercosul na busca pela implantação de políticas alinhadas com o objetivo de transformar a realidade educativa diagnosticada.

O plano referente ao período de 2001-2005 sinaliza textualmente para a educação inclusiva, estabelecendo como meta a promoção de troca de experiências e a formação de um banco de dados sobre o assunto nos países do bloco (MERCOSUL, 2001). Porém, em que pese o estabelecimento de tal meta, o documento não apresentou qualquer definição sobre o que compreende como educação inclusiva, sinalizando apenas referir-se a uma educação universal que tem por finalidade o alcance de todas as pessoas, independentemente de fatos circunstanciais que agem como obstáculos ao processo educacional e, consequemente, ao ensino e à aprendizagem.

Em 2006, foi lançado novo documento com as diretrizes que se estenderam até 2010, registrando que todos os signatários do Tratado de Assunção estavam conscientes de que a educação deveria desempenhar um papel importante, e que o Mercosul não poderia ser subordinado a meros entendimentos econômicos (MERCOSUL, 2006).

Haja vista o desenvolvimento regional, bem como o estabelecimento de uma dinâmica econômica ao bloco, as discussões dos países membros têm se centralizado no fortalecimento da integração efetiva de seus mercados. Para Barboza e Rizzotto (2009, p. 2), "as políticas educacionais, devido ao seu aspecto universalizador, tem sido tratada com grande importância pelos formuladores e agentes estatais, envolvidos numa proposta de integração latino-americana".

Ball (2001) problematiza o "desaparecimento" das políticas específicas do Estadonação e a "universalização" das políticas educacionais pautadas pela competitividade econômica, ou seja, a criação de políticas comuns aos países globalizados. Conforme Mainardes (2006), esta disseminação das influências internacionais pode ser entendida de duas maneiras: a primeira refere-se ao fluxo de ideias por meio de redes políticas e sociais que envolvem a circulação internacional de ideias, o processo de "empréstimos de políticas" e os grupos e indivíduos que "vendem" soluções no mercado político e acadêmico; a segunda diz respeito ao patrocínio e, em alguns aspectos, à imposição de certas "soluções" recomendadas por agências multilaterais (Banco Mundial; Fundo Monetário Internacional; UNESCO; entre outros).

Embora a discussão sobre a educação enquanto um instrumento de integração regional do Mercosul seja latente a partir da premissa da garantia do seu direito, o Plano de Ação (2006-2010) não apresenta objetivos e estratégias mais específicas voltadas para a educação inclusiva. Esse debate fica diluído no tocante a diretrizes mais gerais sobre diversidade linguística e identidade cultural.

Uma das missões presentes no plano de 2006-2010 é a de formar um espaço educativo comum fomentando o intercâmbio regional e promovendo educação de qualidade para todos, para que, como isso, seja possível um desenvolvimento com justiça social e respeito à diversidade cultural dos povos do bloco (MERCOSUL, 2006). Percebe-se que nesse momento, o Mercosul, como autor do plano, acredita que a estratégia para atingir esse objetivo esta estritamente ligada à mobilidade, intercâmbio e formação de uma identidade e cidadania comum na região, o que pode revelar, nessa ótica, prestígio aos princípios da igualdade e da equidade.

O Plano de Ação do Setor Educacional do Mercosul (2011-2015) apresenta elementos já firmados em planos anteriores e reitera a necessidade de fortalecimento das políticas de integração regional, em que a educação desempenha um papel estratégico. Logo, o Setor Educacional do Mercosul, com seus vinte anos de existência e trabalho ininterruptos, 
se constitui como instrumento significativo para a construção de um espaço educacional integrado por meio da coordenação de políticas de educação (MERCOSUL, 2011).

O documento enfatiza que, nas últimas décadas, tem sido consolidada a concepção de educação como um direito humano e um bem público e social. Nesse sentido, destaca que houve avanços na garantia desse direito nos ordenamentos jurídicos dos países da região e considerável aumento nos níveis de cobertura educacional, aliado ao incremento de qualidade.

Entretanto, é apresentada a ponderação de que ainda persiste uma forte desigualdade nos resultados educacionais, permanecendo em situação de vulnerabilidade parte das populações historicamente excluídas. No que tange à integração regional, versa que as políticas educacionais devem incluir conteúdos e ações comuns para a formação de uma identidade regional, com vistas a alcançar uma educação de qualidade para todos, comprometida com o desenvolvimento social (MERCOSUL, 2011).

Sobre a educação inclusiva, o Plano de Ação (2011-2015) destaca a necessidade de elaborar metas e ações visando a uniformização de conceitos sobre a educação, atualmente setorizada, ou seja, sobre a educação especial, indígena e aquelas voltadas para pessoas que sofrem discriminação por causa da cor da pele, utilizando, para tanto, a expressão "afrodescendentes". O documento ainda sugere que os Estados adotem estratégias que promovam debates sobre direitos humanos e conhecimento sobre a diversidade, fomentando os diálogos sobre fatores de exclusão como são as questões de gênero, indígenas, migrantes, população rural, dentre outras.

Percebe-se maior envolvimento do Plano (2011-2015) com a educação inclusiva, especialmente, quando ele ressalta a necessidade de que a diversidade seja devidamente observada nos processos de ensino-aprendizagem, a partir da perspectiva dos direitos humanos. O documento, elaborado por um Setor Educacional mais maduro e experiente, demonstra preocupação com questões interculturais, fronteiriças e inclusivas. Nessa direção, sugere:

[...] sistematizar, editar e divulgar materiais referentes a experiências educacionais que desenvolvam estratégias alternativas sobre os temas prioritários, boas práticas e lições aprendidas na educação inclusiva e para a diversidade: especial, étnica, rural, fronteira, jovens e adultos, entre outros (MERCOSUL, 2011, p. 40).

Com isso, denota-se certo alinhamento do Plano de Ação (2011-2015) com o movimento internacional de "educação para todos", com ênfase em uma educação inclusiva concebida para a diversidade dos alunos, com suas diferenças físicas, sensoriais, intelectuais, emocionais, socioculturais, étnicas, etárias, de origem, de crença e de gênero, dentre outras.

O Plano de Ação vigente, compreende o período de 2016 a 2020. Embora disponível no site oficial do Setor Educacional do Mercosul, o documento é bem sucinto, comparado aos dois últimos, pois apresenta apenas os eixos, objetivos e prioridades das perspectivas das políticas educacionais para os países membros, sem, contudo, contextualizar os marcos gerais do setor, bem como, o balanço atinente às diretrizes dos outros planos.

Nessa direção, o atual Plano de Ação do bloco reitera a necessidade de fomentar políticas educacionais voltadas para a integração regional, mas, diferente dos documentos anteriores, é omisso com relação ao compromisso de assegurá-la enquanto um direito humano. Análises desenvolvidas por Momma (2001), Gadotti (2007), Oliveira (2011) e Souza (2017) demonstram que a educação, embora evidenciada nos Planos de Ação do Setor Educacional do Mercosul como prioridade para a integralização dos países, tem se deparado com o desafio da implantação de políticas públicas que traduzam de fato a efetivação do direito à educação. 


\begin{abstract}
Observa-se a necessidade de desenvolver sistemas educacionais mais equitativos entre os países membros, partes e associados. As disparidades educacionais, no que tange ao financiamento, acesso, permanência, valorização de educadores e investimentos em áreas relacionadas ao desenvolvimento educacional precisam ser tema prioritário nas agendas políticas, nos debates locais e regionais e em especial necessitam de ajustes no sentido de estar imbricadas em uma estratégia de desenvolvimento que não se esgota com aproximação de diferentes contextos e culturas, mas que se fortalece na medida em que se articula, se expande e se consolida como projeto em construção. (OLIVEIRA, 2011, p. 234)
\end{abstract}

No que concerne à educação inclusiva, denota-se no plano em vigor apenas a previsão de desenvolvimento de oportunidades de inclusão e participação para atender as necessidades socioeducativas dos estudantes (MERCOSUL, 2016). Assim, o documento estabelece uma vinculação entre inclusão e participação na sociedade a partir da inserção do indivíduo no sistema educacional, embora não indique, de forma expressa, quais são os problemas que os Estados membros devem enfrentar e sobre quais questões específicas precisam atuar nas implicações entre educação-sociedade.

Beshara e Pinheiro (2008) argumentam que as definições de acordos constantes nos Planos de Ação orientam as políticas de integração para o Mercosul, focalizando como objetivo a efetiva contribuição para a integração regional, a partir de acordos e execução de políticas educacionais que estejam articuladas com um projeto de cidadania regional, mas que não tem logrado êxito na garantia e, sobretudo, na efetivação da educação enquanto direito. Entre o anúncio do direito à educação e a efetivação deste, há uma grande distância.

De acordo com Bobbio (1992, p. 10),

\begin{abstract}
Uma coisa é proclamar esse direito, outra é desfrutá-lo efetivamente. A linguagem dos direitos tem indubitavelmente uma grande função prática, que é emprestar uma força particular às reivindicações dos movimentos que demandam para si e para os outros a satisfação de novos carecimentos materiais e morais; mas ela se torna enganadora se obscurecer ou ocultar a diferença entre o direito reivindicado e o direito reconhecido e protegido.
\end{abstract}

Sem desconsiderar as importantes e necessárias tentativas de justificar os direitos sociais, Bobbio (1992) afirma que, na atualidade, é a garantia e não os fundamentos dos direitos que precisam ser assegurados e protegidos. Para ele, o importante não é fundamentar os direitos do homem, mas protegê-los e, para isso, não basta apenas proclamá-los.

Nessa direção, Nozu, Icasatti e Bruno (2017, p. 32), ao analisarem a emergência da educação inclusiva enquanto um direito humano, indicam que a vida de um direito só é possível por meio de lutas permanentes: "para a conquista, para a materialização/efetivação, para a ampliação e contra o retrocesso do direito previsto".

\title{
CONSIDERAÇÕES FINAIS
}

A educação é um direito consagrado em documentos político-normativos internacionais e nacionais, materializados por meio de declarações, convenções, acordos bi ou multilaterais, planos de ação, constituições, leis, resoluções, dentre outros. Trata-se de um direito conclamado com caráter de universalidade, cujo efeito discursivo pretendido, nas últimas décadas, consubstancia-se na adjetivação da educação como qualitativa, equitativa e inclusiva. 
Neste texto, buscou-se, especificamente, analisar o direito à educação inclusiva na documentação do Setor Educacional do Mercosul. Os dados apresentados denotam o reconhecimento do Setor Educacional do Mercosul sobre a importância da educação como estratégia para o desenvolvimento econômico e para a integração regional.

Há que se levar em consideração o fato do Mercosul ser um bloco econômico criado para sobreviver ao mercado globalizado, creditando na educação a potencialidade de tornar as pessoas ativas no mercado de trabalho-consumo, o que, via de consequência, serve como mola propulsora para a economia. Ao se conscientizar disso, a educação inclusiva também pode ser encarada, além de uma premissa da diversidade, como uma ferramenta utilizada para expandir a produção e o consumo, ou seja, fortalecer a circulação de bens e serviços na região, o que, por sua vez, promove o desenvolvimento econômico regional.

Isso porque a preocupação com a exclusão social sofrida por alguns grupos de pessoas em situação de vulnerabilidade, assim como a resolução desse problema deve ser pautado como um dos expedientes dos sistemas educacionais dos países do Mercosul para o enfrentamento de crises econômicas e para favorecer a integração dos povos, também encarada como uma tática para manter os Estados competitivos e presentes no mercado do capitalismo global.

Além disso, da análise realizada nos Planos de Ação do Setor Educacional do Mercosul, evidenciam-se lacunas na produção documental do referido bloco no tratamento da educação inclusiva, sobretudo quanto aos conceitos e ao modus operandi para sua consecução. Dentre os Planos de Ação, o que compreende o período de 2011-2015 é o que parece mais atentar-se à temática da educação inclusiva, associando-a ao discurso da diversidade e sinalizando um cuidado especial a alguns grupos marginalizados pela condição de deficiência, de origem, étnica, etária etc.

Por fim, é preciso indicar a presença na documentação do Setor Educacional do Mercosul de uma visão de educação redentora, salvacionista e messiânica dos problemas sociais, da qual as elucidações sobre a educação inclusiva também são tributárias e subjacentes.

\section{REFERÊNCIAS}

AINSCOW, M. Tornar a educação inclusiva: como esta tarefa deve ser conceituada? In: FÁVERO, O. et al (Org). Tornar a educação inclusiva. Brasília: UNESCO, 2009. p. 11-23.

AKKARI, A. internacionalização das políticas educacionais: transformações e desafios. Petrópolis: Vozes, 2011.

BABINSKI, D. B. de O. O direito à educação básica no âmbito do Mercosul: proteção normativa nos planos constitucional, internacional e regional 2010. 182f. Dissertação (Mestrado em Direito) - Universidade de São Paulo, São Paulo, 2010.

BALL, S. J. Diretrizes políticas globais e relações políticas locais em educação. Currículo sem Fronteiras, v. 1, n. 2, p. 99-116, jul./dez/ 2001. 
BARBOZA, M. de J; RIZZOTTO, M. L. F. Educação e integração regional no Mercosul. In: SEMINÁRIO NACIONAL ESTADO E POLÍTICAS SOCIAIS, 4, 2009, Cascavel. Anais... Cascavel: Unioeste, 2009.

BESHARA, G.; PINHEIRO, L. Educação e política externa: a experiência brasileira no Mercosul Educacional. In: Relatório de Pesquisa "Política Externa e Educação - um estudo comparativo sobre a atuação do Brasil na CPLP e no Setor Educacional do Mercosul”, Rio de Janeiro: Instituto de Relações Internacionais da PUC-Rio, 2008.

BOBBIO, N. A Era dos direitos. Rio de Janeiro: Campus, 1992.

BUENO, J. G. S. As políticas de inclusão escolar: uma prerrogativa da educação especial? In: BUENO, J. G. S.; MENDES, G. M. L.; SANTOS, R. A. Deficiência e escolarização: novas perspectivas de análise. Araraquara, SP: Junqueira\&Marin; Brasília, DF: CAPES, 2008, p. 43-63.

GADOTTI, M. O Mercosul Educacional e os desafios do século 21. Brasília: Instituto Nacional de Estudos e Pesquisas Educacionais Anísio Teixeira, 2007.

GLAT, R.; PLETSCH, M. D. Inclusão escolar de alunos com necessidades especiais. Rio de Janeiro: EdUERJ, 2011.

HEREDERO, E. S. A escola inclusiva e estratégias para fazer frente a ela: as adaptações curriculares. Revista Acta Scientiarum, Maringá, v.32, n.2, p.193-208, 2010.

MAINARDES, Jefferson. Abordagem do ciclo de políticas: uma contribuição para a análise de políticas educacionais. Educação \& Sociedade, Campinas, vol. 27, n. 94, p. 47-69, jan./abr. 2006.

MATEUS, D. P. A Efetividade do direito à educação no Brasil e Mercosul: o Tratado de Assunção e a Educação. 2008. 88f. Dissertação (Mestrado em Direito Internacional) Universidade Católica de Santos, Santos, 2008.

MENDES, E. G. Breve histórico da educação especial no Brasil. Revista Educación y Pedagogía, v. 22, n. 57, p. 93-109, 2010.

MERCOSUL. Plano de Ação do Setor Educacional do Mercosul 2001-2005. Brasil: Instituto Nacional de Estudos e Pesquisas Educacionais Anísio Teixeira, 2001. 
MERCOSUL. Plano de Ação do Setor Educacional do Mercosul 2006-2010. Brasil: Instituto Nacional de Estudos e Pesquisas Educacionais Anísio Teixeira, 2006.

MERCOSUL. Plano de Ação do Setor Educacional do Mercosul 2011-2015. Brasil: Instituto Nacional de Estudos e Pesquisas Educacionais Anísio Teixeira, 2011.

MERCOSUL. Plano de Ação do Setor Educacional do Mercosul 2016-2020. Brasil: Instituto Nacional de Estudos e Pesquisas Educacionais Anísio Teixeira, 2016.

MOMMA, A. M. As políticas educacionais brasileiras do ensino fundamental no contexto do Mercosul: perspectivas e desafios para o processo de integração. 2001. Dissertação (Mestrado em Educação) - Universidade Estadual de Campinas, Campinas, 2001.

NOZU, W. C. S.; ICASATTI, A. V.; BRUNO, M. M. G. Educação inclusiva enquanto um direito humano. Inclusão Social, Brasília, DF, v.11, n.1, p.21-34, jul./dez. 2017

OLIVEIRA, O. S. Políticas educacionais brasileiras, integração latino-americana e o Mercosul educacional: questões para o debate. Revista HISTEDBR, Campinas, n. 43, p. 223236, 2011.

SCHILLING, F. O direito à educação: um longo caminho. In: BITTAR, E. C. B. (Org.). Educação e metodologia para os direitos humanos. São Paulo: Quartier Latin, 2008. p. 273284.

SOUZA, K. R. Direito à educação nos países membros do Mercosul: um estudo comparado. 2017. 346f. Tese (Doutorado em Educação Escolar) - Universidade Estadual Paulista, Araraquara-SP, 2017.

SOUZA, K. R.; NOZU, W. C. S.; KERBAUY, M. T. M. Educação como um direito humano: análise das declarações de Jomtien, Dakar e Incheon. In: BRUM, A. K.; ESPÓSITO NETO, T.; CONTINI, A. A. M. (Orgs.). Desenvolvimento para além das fronteiras: diálogos sobre aspectos sociais, culturais e regionais. Curitiba: Appris, 2018, p. 165-183.

UNESCO. Declaração de Salamanca sobre princípios, políticas e práticas na área das necessidades educativas especiais. Salamanca, Espanha: UNESCO, 1994.

Recebido em: 10/01/2018

Aceito em: 10/02/2018 